\title{
THE BRITISH
}

\section{JOURNAL OF DERMATOLOGY.}

\author{
A U GUST, 1902.
}

\section{PEMPHIGUS VEGETANS.}

By W. ALLAN JAMIESON, M.D., AND D. A. WELSH, M.D., F.R.C.P.E., F.R.C.P.E.,

Lecturer on Diseases of the Skin, University of Edinburgh; Phy-

Professor of Pathology, Universician for Diseases of the Skin, Royal Infirmary, Edinburgh. sity of Sydney, N.S.W.; late Pathologist to the Royal Infirmary, Edinburgh.

Thолgн more than fifty instances of Pemphigus vegetans have been recorded since Neumann first described it in 1886, yet only one example has hitherto been observed in this country by Crocker, though Hutchinson has seen cases apparently referable to this class. The following one therefore appears worth relating on clinical grounds, while the peculiar and important changes in the nervecells discovered by Dr. Welsh open up a new chapter in its history.

On the 27th September, 1899, Dr. Park, of Johnstone Bridge, asked me to see, in consultation with him, an anomalous case of pemphigus which had been under his care for some time, but which steadily and progressively grew worse. The patient was the wife of a farmer in the district, was aged 32 , had been born and brought up in the neighbourhood, and had, till June, 1899, been uniformly healthy. She had been married for eighteen months, and had an infant nearly nine months old, which she had nursed up to the time of the commencement of her illness. The farmhouse where she lived was a two-storey building, not of very modern construction, but comfortable. There was, however, in the courtyard behind the house, and closely adjoining it, what might be termed a " midden," a place 
thickly strewn with straw, saturated with the dung and urine of cattle and horses, to be subsequently employed as manure. This is still common enough in many farm-steadings, and was a state of matters to which she must have been well-inured. The months of June, July, and August-pariicularly the two last-were in that year very warm and dry. The disease commenced in the mouth. Blisters and raw places formed inside the cheeks, the tongue hurt these in mastication, and an offensive odour exhaled from the oral cavity. Some decayed teeth were removed. After lasting two months, in the early part of August blebs appeared in the vicinity of the genitals and anus, and constantly extended to new areas. She struggled on till the middle of September, when she was compelled to take to bed.

When seen she was markedly thin and emaciated, her integument was sallow, and a nauseous odour of a peculiarly penetrating character, which permeated the room and was perceptible even beyond it, proceeded from the surface. The interior of the mouth was covered with sordes, as also the tongue, but she did not complain of pain in it. The gums were spongy and bled readily, the teeth were dark, small, and much decayed. The tongue was red and dry, and she was thirsty at times. The lips were swollen and crusted, and scattered over the face were bullæ. In the axillæ were fungating growths or vegetations, rising half an inch above the surface, and brownish red in colour. There was a crusted vegetation at the umbilicus. The entire lower part of the abdomen, the puber, inside of the thighs and groins, and extending back to the anus, were studded with bullæ, some tense, some flaccid, between which were crusts. The margin of the affected region was bounded by a red areola, half an inch broad. In the groin were some sloughs and some vegetations, but these were not so prominent as those in the axillæ, though well marked. Some of the details were concealed by a covering of powder or calamine lotion which had been applied to relieve. There were also blebs and crusts on the inner side of the legs, and there, too, was an isolated bulla, the size of a pigeon's egg, with pale, strawcoloured contents. The dorsum of the feet and sides of the ankles were likerwise crusted and bore bullæ. The same condition was visible on the arms, and especially at the elbows, but in that locality there was manifested a disposition to a certain amount of healing. It was 
impossible to turn the patient round, so the state of the dorsal region was not noted. The urine was scanty, and as a rule only passed twice in twenty-four hours; was alkaline, and contained phosphates but no albumen. The pulse was fairly strong and regular. The temperature was not taken, but she did not complain of being hot at night. A blister from which the roof had been removed showed an erosion round the sides, and a whitish, raised, and œdematous centre. The disease had progressed by peripheral extension.

As it was found on inquiry that her diet had contained few fresh green vegetables, these were directed to be added to it. A fairly mixed regimen was prescribed, but in consequence of the tenderness of the mouth, salt and condiments were proscribed, and milk and articles made with milk were to be the staple diet. Locally, the parts were to be soothed and cleansed by the application of boric starch jelly as a poultice, the skin being gently wiped on the removal of one and before the application of another. When by these means the crusts and decayed epithelial aceumulations had been cleared away, an oleo-calcareous liniment, composed of chalk, oxide of zinc, olive oil, lime-water and boric acid was to be freely painted on. Internally a mixture of arsenic, strychnia, and hydrochloric acid, with full doses of cinchona in the form of the compound tincture, was ordered. For the mouth hazeline or listerine diluted with warm water was recommended; the former proved of little value, but the latter gave much relief.

It was found that from the wideness of the area to which the cold boric starch jelly had to be applied, the chilling effect was too severe, and collapse was threatened. Thus this had to be cautiously employed. The liniment above mentioned was therefore chiefly used. Dr. Park kindly kept me informed from time to time of her progress. On the 4th October he stated that the root of the tongue had become ulcerated and painful, and that the bowels gave trouble from constipation, notwithstanding the administration of a drachm of the liquid extract of cascara at night, and a wineglassful of Friedrichshall water in the morning. On the 31st October Dr. Park wrote that the disease had kept coming and going. It might remain quiescent for a week, then improve a little, still, however, continuing to spread so that it had invaded the whole of the limbs, the abdomen, across the hips, and up the centre of the back. The feet had become rather 
better, also the part of the abdomen where first attacked. For the last four weeks the blebs had been, as a rule, smaller, and such tended to heal up, but should they run together to form a large bulla, this healed with great difficulty, and if the situation was a moist one, the floor produced vegetations. For the last six days some erythematous spots had appeared, as well as a zone of erythema round the diseased and healing parts. The skin under this felt tough and velvety, and in places a dry desquamation occurred. At times a rare vesicle arose in an erythematous zone. The general health was wonderfully maintained. The liniment proved the best local application. The dose of arsenic, the liq. arsenici hydrochloricus, had been increased from five to ten minims thrice daily.

On the 18th December, 1899, Dr. Park reported that the bullæ had become steadily smaller and smaller, and that beneath scabs which tended to form, healthy epidermis grew. The fungations shrank and finally disappeared. She was then able to sit up for eight hours daily, her appetite was good, and all the physical functions normal. The same treatment had been adhered to all through, only latterly in addition to the arsenic, strychnia, and cinchona, she had some Fellows' and Easton's syrups combined. "She may now be said to have recovered." She was not, however, able for much housework. The skin was stained a light brown where the eruption had been most copious.

On the 5th February, 1900, her husband called on Dr. Park to tell him that some piles which had been troublesome had again proved annoying, and that he feared a relapse was impending. In fact Dr. Park discovered on examination that there were some blebs on the extensor aspect of the forearms. The legs and feet were considerably swollen, and on the latter there were also some bullæ. The general surface was erythematous, not unlike the appearance round the previous eruption when in process of fading. The urine had again become scanty. She continued to grow worse, many bullæ coming out, till the date of her admission to my ward in the Royal Infirmary on 30th April, 1900.

What struck one at once was her emaciation, and the dark pigmentation of her skin. This varied in different parts, but was of a very dark brown, or even in places of a purplish hue. There were few if any blebs on the upper half of the body, though a number 
came out subsequently on the lower limbs. All over her were large raw surfaces, some crusted, some merely raw. Except on the legs the raw places healed under the continual application of zinc ichthyol salve muslin. Her tongue was always dry and fissured, though not so tender as previously. She wasted more and more, though her appetite was good, sometimes ravenous. The urine did not contain any albumen or sugar. Her pulse varied between 88 and 106 . The temperature constantly rose in the evening, was irregular, its highest being $103 \cdot 6$, while it was at times normal in the morning. Her respirations ranged from 22 to 24 per minute. She had a soft cough but no expectoration, but the state of her skin was such that no satisfactory examination of her lungs could be made.

On May 3rd Dr. Gulland kindly made an examination of fluid from fresh blebs, and reported that there were no streptococci in it, and no eosinophiles. The cells were scanty, and were all degenerated neutrophiles. This examination was made for streptococci, because in a case of pemphigus, in a lad at the same time in my male ward, whose case in some respects resembled Mrs. L.'s, Dr. Gulland had found numerous streptococci in the fluid from recent blebs.

The marasmus continued to increase till, except on the abdomen, where there still remained a degree of subcutaneous fat, she was literally skin and bone. Though on a water-bed with every precaution taken, bed-sores formed on the back and hips, and she died exhausted in the end of June.

The autopsy was conducted by Dr. D. A. Welsh, now Professor of Pathology in the University of Sydney, who has kindly furnished me with the following report:-

"The body was extremely emaciated. The skeletal muscles were greatly atrophied, and in a state of permanent contracture, the lower limbs especially being rigidly flexed. The skin presented an extensive brownish discoloration with numerous cicatrices both old and recent.

Thorax.-The heart weighed 9 ozs., and showed slight chronic thickening of the pericardium and of the aortic valve segments. The myocardium of the left ventricle was wasted and anæmic, but that of the right ventricle was hypertrophied.

The left lung, weighing 15 ozs., was emphysematous and anæmic. The right lung, weighing 28 ozs., showed chronic thickening of the 
pleura, particularly over the upper lobe, which, on section, was found to be studded with chronic tubercle nodules, and riddled with numerous small cavities containing caseous débris. The condition was one of chronic tubercle with more recent acute phthisis. The lower lobe was congested and infected with extensive acute tuberculosis. The bronchial glands at the root were enlarged and caseous.

Abdomen.-The peritoneum as a whole was healthy, but a localised patch of chronic peri-hepatitis had produced adhesions between the under surface of the liver and the cardiac end of the stomach. The liver itself was enlarged from advanced fatty infiltration, and showed slight chronic congestion. The stomach exhibited no ulceration. The spleen was much enlarged, weighing $21 \mathrm{ozs}$., soft and diffluent throughout and of a uniform reddish colour. Its appearance closely resembled those met with in conditions of septic absorption. The kidneys weighed 8 ozs. each, and showed patches of recent catarrh and congestion, in addition to chronic interstitial changes.

Nervous System.-The brain weighed 49 ozs. The convolutions over the vertex were atrophied, and the widened sulci contained excess of cerebro-spinal fluid. Over the inner surface of the dura mater, and to an equal extent on each side, there were numerous patches of congestion and very extensive formation of a delicate brownish membrane-an early condition of pachymeningitis hæmorrhagica interna. The cerebral vessels and sinuses were healthy. The cerebrum on section was very watery and cedematous. The grey matter of the pons was slightly injected.

The spinal cord showed no alteration obvious to the naked eye, but sections stained by the Weigert-Pal method showed a slight but widespread marginal sclerosis, with rarefaction and atrophy of the fibres.

Sections of the spinal cord, cerebral cortex, and sympathetic ganglia were submitted to Dr. Ford Robertson, who kindly supplied the following report and prepared the photo-micrographs which illustrate the changes described in the nerve-cells of the spinal cord :-

"The cervical and dorsal cord, cervical sympathetic ganglia, and cerebral cortex have been examined in toluidin blue preparations. The nerve-cells of the spinal cord show well-marked degenerative 
changes of a special character, consisting of an evidently slowly progressive rarefaction of the chromophile bodies of the protoplasm,

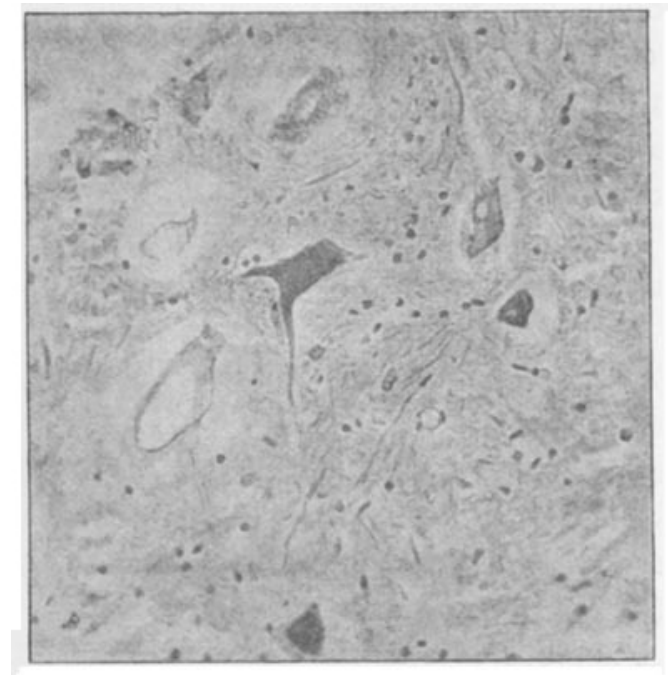

Fia. 1.

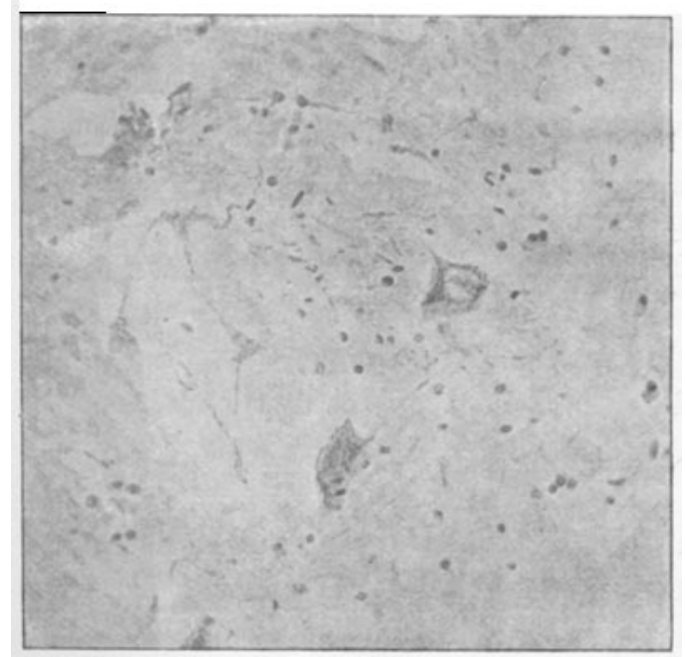

FIG. 2.

To illustrate Jamieson and Welsh's paper on Pemphigus vegetans, showing degenerative ehanges in the nerve-cells of the anterior cornua of the cervical region of the spinal cord.

more especially in the perinuclear zone, formation of minute 
vacuoles in the altered portion of the protoplasm, swelling of the cell-body, disintegration of the nucleus, and finally destruction of the whole element. The nerve-cell pigment is only slightly increased. Every nerve-cell in the sections of the cord examined shows this change in some measure. About one-fourth of the cells present an extreme degree of alteration. No special group of cells appears to be affected more than another, though the extreme type of change shown in the photographs occurs only in the cervical region. The morbid process has been essentially a diffuse one.

"Changes similar in character, but much less advanced, are present in the nerve-cells of the sympathetic ganglia and of the cerebral cortex.

"The vessels of the nervous tissues do not appear to lave undergone any very distinct alteration.

"These nerve-cell changes represent a form of primary degeneration. Alterations of a similar character and diffuse in distribution throughout the nervous system are occasionally observable in cases of acute insanity."

There are two secondary changes which may occur in pemphigus. One is parakeratosis, of which pemphigus foliaceus is the type. The other is acanthosis with participation of the corium, of which pemphigus vegetans is the representative. Both eventualities, as well as the pemphigus itself, are apparently ascribable to toxins, but the organisms hitherto isolated from the contents of the bullæ are of such divergent species that one cannot with any certainty incriminate a particular one. As to the point of entrance in pemphigus vegetans, from the early implication of the mouth and its lining, it would seem possible that the organism may have been implanted there. Such a situation gives ample scope for subsequent luxuriant growth, and favours the extensive saturation of the system. The cutaneous lesions and the modifications in the nerve-centres appear to be due to the same cause, the toxin acting destructively on the nerve-cells, and at the same time stimulating those of the skin. This view is also held by Köbner," who remarks: "The pathological and certainly rare changes in the nervous system (spinal cord, Ehrmann; upper cervical ganglion, Marianelli) are, I think, secondary and depend on some bacterial toxin. That some such intoxication agent is at work * "Selected Essays aud Monographs," New Syd. Soc., 1897, p. 166. 
is practically shown in those cases of bullous toxidermatites with vegetations resembling venereal warts (condylomata acuminata) (Trafesnikow), or, as in Hallopeau's case, after potassium iodide." Neumann has observed that "the longer the disease lasts, the less the tendency to formation of vegetations; on the other hand, the development of blebs becomes more pronounced."* As to the localization of the lesions in the nervous system, the sole observation which I have discovered at all comparable to ours is that of Brocchierit in a case of pemphigus simplex. Besides hæmorrhages and changes in the walls of the vessels, he found "that the multipolar cells of the arterior cornua and of Clarke's columns contained masses of colouring matter evidently formed from extravasated blood-corpuscles, and showed in places degeneration of both nucleus and protoplasm."

The photomicrographs were made in the Laboratory of the Scottish Asylums, and the prints from these by Mr. Richard Muir. These admirably represent the appearances seen in the anterior cornua of the seventh or eighth cervical segments of the spinal cord.

\section{SOCIETY INTELLIGENCE.}

\section{DERMATOLOGICAL SOCIETY OF LONDON.}

AN ordinary meeting of the Society was held on Wednesday, July 9 th, 1902, Dr. J. J. Pringle in the chair. The following cases and specimens were shown:-

Dr. S. E. Done showed three cases of Psoriasis following raccination. In two of the cases the attacks were primary, in the third there was a history of a previous skin-eruption. The notes were as follows :-

(1) A young man, aged 20 years, a stonemason by occupation, was re-vaccinated at the beginning of December, 1901, in four places. Three of them took successfully and ran the usual course. On the eighth day, when the sites of vaccination were covered by scabs, a

* "Selected Essays and Monographs," New Syd. Soc., 1897, p. 176.

† Abst. in Brit. Journ. of Dermat., January, 1899, p. 41. 